\title{
Neoliberalismo, Estado y Bienestar Social en México.
}

\author{
Martín Rodríguez Peñaloza \\ Centro de Investigación y Estudios Avanzados de la Población UAEM
}

\begin{abstract}
"Por grande o pequeña que sea, la función positiva del Estado (no solamente impedir sino también promover, no solamente proteger sino también impulsar),..no basta la justicia conmutativa -cuantitativa- ...que consiste en hacer corresponder al bien (o al mal) cumpliendo un bien (o un mal) igualo contrario con base en el criterio de igualdad aritmética...es necesario, algún criterio de justicia distributiva -cualitativa”(Bobbio, 1986: 88)
\end{abstract}

\section{Introducción}

El presente ensayo tiene como finalidad mostrar algunos de los efectos del modelo neoliberal implantado en México a principios de la década pasada y la necesidad de un modelo alternativo de desarrollo, que se ajuste a las condiciones actuales, y que coadyuve a superar la crisis actual, redundando en un mejoramiento de las condiciones de vida y/o los niveles de bienestar de población.

Para poder entender las causas de la implementación del modelo neoliberal en nuestro país, es necesario hacer una reseña de la reconversión que se dio, al pasar de un Estado intervencionista a un Estado con una participación mínima, donde las formas de negociación y/o participación económico-político-laboral están cambiando, -proceso de cambio de una relación macro a una relación micro- lo que está afectando las formas de participación en los beneficios, no únicamente económicos y políticos, sino también sociales.

Las experiencias dejadas por el Estado benefactor y el neo liberalismo -en lo que va de su implementación-, han ocasionado desequilibrios no únicamente económicos sino principalmente sociales, lo que se observa en la fuerte caída, en los últimos años, en los niveles de bienestar de la población.

Resultado de lo anterior, ha sido la incapacidad de respuesta ante la crisis, tanto del Estado como del mercado. De aquí la necesidad de buscar nuevas formas de organización, donde se involucren no únicamente a los actores 
representantes de los sectores público y privado, sino también a la sociedad, en la generación e implementación de la política económica y social, donde se conjuguen las intervenciones, reguladas y/o acotadas, del mercado y del Estado, respetan- do espacios de intervención, en aras de dar eficiencia al sistema productivo y político, y eficacia en las formas de distribución que induzcan a una redistribución del ingreso, elevando los niveles de bienestar, que contribuyan a ir erradicando los niveles de pobreza, que se han alcanzado en México, sobre todo a partir de la adopción y adaptación del modelo llamado neo liberal.

La forma en que quedó estructurado el presente ensayo es la siguiente: en la parte 1. El Neoliberalismo, se habla de algunas generalidades del modelo neoliberal; en la parte 2. El Mercado Político-Económico-Laboral de lo Macro a Lo Micro, se trata sobre los cambios que se están dando en dichas relaciones al pasar de un Estado de bienestar a un neoliberalismo; en la parte 3. Mercado, Estado-Gobierno y La Politica Social, en esta parte se muestran algunos de los efectos provocados por el modelo neo liberal, en los niveles de bienestar de la población -caída de los mismos-; en la parte 4. Necesidad de un Modelo Alternativo de Desarrollo, se hace mención de algunos aspectos a considerar para la conformación de un nuevo modelo, y; finalmente en la parte 5. A Manera de Conclusión, se hacen algunos comentarios al respecto.

\section{El neoliberalismo ${ }^{1}$}

Ante la crisis económica, política, social y cultural, en la que actualmente estamos insertos, se presenta otra crisis, no menos importante, la inexistencia de un modelo teórico o paradigma que dé o trate objetivamente de responder a las exigencias y/o problemas que padecemos hoy en día, tales como pobreza, pobreza extrema, desempleo, baja productividad, centralismo, independencia, "soberanía", endeudamiento, falta de crecimiento y desarrollo, entre otros.

1 Lo podemos caracterizar de la siguiente manera: "El neoliberalismo económico, en general, tiene las siguientes características: a) una cada vez menor intervención del Estado en la economía, cuya contraparte es el creciente papel de los 'mecanismos de mercado' en la asignación de los recursos productivos y en la orientación y dinámica del sector económico; b) la transferencia de propiedades de todo tipo del sector público al privado; c) apertura de la economía al comercio y al flujo de capitales al exterior; d) se otorga una alta prioridad a los equilibrios macroeconómicos, tales como el fiscal, los precios y el sector externo, siendo este esencial para la preservación de un tipo de cambio alto (moneda nacional sobrevaluada); y e) programas específicos orientados a mitigar la pobreza.(Ornelas, 1995:12). 
La crisis teórica se refleja -después de la caída del socialismo, que era la opción alternativa- en el resurgimiento del liberalismo y neoclasicismo, ahora llamado neoliberalismo.

La doctrina liberal, hoy más que nunca, está presente en dos de los ámbitos teóricos más importantes: el económico y el político -con sus obvias implicaciones sociales-.

En la teoría económica, el liberalismo (neoliberalismo) es partidario de la economía de mercado: en el caso de México, Rodríguez Araujo diría que el imperativo de la modernización, bajo el modelo neoliberal, se caracteriza por la organización del país para producción de riqueza y bienestar, distribuirla equitativamente, respetando la iniciativa comunitaria y la superación personal; lo anterior lo resume en: producción de riqueza, darwinismo social e individualización de las relaciones sociales de producción.

En la teoría política, el liberalismo (neoliberalismo) es partidario del Estado que gobierne lo menos posible -reducción del Estado al mínimo-: en México, existe la necesidad de aumentar el peso del ciudadano y el de las organizaciones sociales en la formación y en la conducción del estado, menor intervención de éste, abandono de la tradicional política social y de subsidios, y utilización discrecional de recursos estatales para resolver las contradicciones sociales provocadas por la acumulación capitalista (Rodríguez, 1991).

Ahora bien, “...el pensamiento liberal tiene dos caras: una es la reivindicación de las ventajas de la economía de mercado contra el Estado intervencionista, por otra es la reivindicación de los derechos humanos contra toda forma nueva de despotismo" (Bobbio, 1986: 91). Capitalismo sí, todo lo que huela a socialismo no.

Actualmente el liberalismo económico o neoliberalismo, es el que en la arena económico-política, se ha levantado con la "victoria" -caída del bloque oriental ("socialista")- pero ante la falta de rivales, éste también está en crisis, por su incapacidad mostrada, no únicamente de ahora, para atender los nuevos retos planteados por la crisis económica, política y social.

Ante los fracasos del Estado capitalista encubierto, como Estado benefactor, y el Estado socialista, que pregonaba la justicia social, destruyeron la libertad, la capacidad de desarrollo individual, como un niño que desde la cuna hasta la tumba es conducido por la mano de un padre, que todo lo resolvía, o mejor dicho, trataba de resolver.

La economía y la política son procesos que se retroalimentan, la relación entre estos procesos sociales es muy estrecha y, en varios sentidos determinante en forma recíproca. La política económica y la naturaleza misma de 
la economía tiene un efecto directo sobre la estructura del sistema político y viceversa (CIDAC, 1990), "El problema de la relación entre la economía y la política no es algo nuevo. Para el México de los noventa, sin embargo, esta relación resulta crítica, como ya lo ha sido en otras etapas de su historia. Algunas de estas relaciones que caracterizan a la economía y a la política son por demás obvias una situación caótica en la economía puede traer consigo un rápido deterioro político." (CIDAC, 1990: 50).

Entonces, si la teoría que prevalece actualmente es el neo liberalismo, bajo la forma de un "capitalismo de merca- do, moderno, salvaje", es conveniente explicar los cambios que se han dado en las relaciones del moderno mercado, es decir, los cambios ocurridos en los ámbitos del mercado políticoeconómico en México y sus efectos sociales.

\section{El mercado político-económico-laboral: de los macro a lo micro}

Para explicar lo anterior, retornaremos una de las ideas de Max Weber, que fue desarrollada y difundida por Schumpeter, mismo que decía que así como existe un mercado económico, también existe un mercado político, ya que el principio weberiano menciona “...que el líder político es comparable con un empresario -cuya ganancia es el poder y cuyo poder se mide con votos, cuyos votos dependen de la capacidad de satisfacer los intereses de los electores y cuya capacidad de respuesta a la demanda de los electores depende de los recursos públicos de los que puede disponer “

(Bobbio, 1986: 97).

A partir de lo anterior podemos hablar de una transición que se está dando en el mercado político y en el mercado económico-laboral, transición de lo macro a lo micro.

El Estado mexicano que por varias décadas, hasta principios de la pasada, se caracterizó por ser un Estado intervencionista y/o de bienestar -con un extraordinario y amorfo crecimiento-, que se hizo cargo, o mejor dicho, vendió amplias funciones sociales -lo que incluyó, obviamente, un fuerte gasto social- a cambio de un tutelaje de las libertades ciudadanas. Esto fue posible, gracias al fuerte corporativismo, donde se reproducía el esquema benefactor; es decir, donde los líderes políticos, representantes gremiales, negociaban en los ámbitos privado y público, mejoras económicas, políticas y/o sociales. Las negociaciones se realizaban a nivel rama, a nivel sector, esto es a nivel macro; la disponibilidad de recursos financieros permitió, de alguna manera, una negociación --distribución político-financiera-- tras bambalinas, los votos para el político y/o para el partido, estaban garantizados. El Estado be- 
nefactor, protegía a los ciudadanos y entre ellos a los empresarios, al imponer una cortina proteccionista que volvió ineficiente a las instituciones, al mercado y a la planta productiva. Y no únicamente eso, sino que la contracción de la economía y la "pasividad política de la ciudadanía", nos llevaron a la actual crisis de las estructuras económica, política y social.

Lo anterior condujo al resurgimiento del liberalismo, hoy llamado neo liberalismo, acusando éste al Estado benefactor no solamente de violar el principio del Estado mínimo, sino también de haber creado un Estado -Estado débil- que ya no lograba desarrollar su propia función, que es la de gobernar.

Así tenemos que desde principios de la década de los ochenta, México fue adoptando y adaptando ${ }^{2}$ un "nuevo modelo", el neoliberalismo. Ante tal situación de crisis, las relaciones mercantilistas entre el gobierno, los partidos políticos y los empresarios, para con la población, cambia; ante un Estado que se ha ido reduciendo, ante una crisis económica que redujo sustancialmente los recursos financieros -fuerte contracción del gasto social-, ante una incorporación más activa de los ciudadanos, y ante los cambios en la gestión y formulación de las políticas, antes netamente gubernamentales, ahora en camino a ser sociales -se ha dado un avance en el marco legislativo de participación local-; las transacciones del mercado se van individualizando, es decir, surge y se va fortaleciendo una relación macroeconómica, en detrimento del mercado corporativista a ultranza. La población en general, para vender un voto a los líderes y/o actores políticos, lo hace cada vez menos a través de sus viejos representantes, ahora de alguna manera se está dando, cada vez en mayor medida, una transacción más sectorizada y/o venta más individual; es decir, qué beneficio personal se recibe a cambio o por la venta del voto; los trabajadores tienen una relación laboral, contractual, donde la tendencia es a ya no ser fuertemente representados por el líder, sino que la relación se da de una forma con fuerte tendencia individual de acuerdo a su productividad -el beneficio por la venta de su fuerza de trabajo está en función de su productividad marginal-, a sus necesidades, a sus intereses, optimización individual. ${ }^{3}$

2 La ideología contenida en el neoliberalismo, se caracteriza, como bien dice René Villarreal, por cierta posición bastante clara: si el modelo neoliberal no se ajusta, en muchas de las ocasiones a la realidad, entonces hay que ajustar la realidad al modelo.

$3 \mathrm{El}$ proyecto ideológico liberal (hoy neoliberal) se caracteriza o se puede expresar de la siguiente forma: "El desarrollo del 'individualismo' lleva al crecimiento y desarrollo óptimo de la sociedad, pues a través del libre juego del mercado...se encarga de eliminar a los menos eficientes y sólo sobreviven los más capaces (Darwin)... (Hoy llamado darwinismo social). El libre juego del sistema de precios de mercado lleva al 'desarrollo' justo de la sociedad, al dis- 
Esto último aparece en la "...hipótesis de la que parte el contractualismo moderno,...un Estado en el que solamente existen individuos aislados, pero tienden a unirse en sociedad para salvar la vida y la libertad. "(Bobbio, 1986: 100). Lo anterior trajo consigo una reconversión en las formas de redistribución de la riqueza generada, y en los niveles de bienestar, resultado en cierta medida por la reconversión en las formas de negociación político-laboral.

Es indudable que en los últimos 13 años, se ha dado una extraordinaria modificación en el ámbito laboral y sus formas de negociación en nuestro país, "Y no ha sido para menos...en ese lapso las relaciones laborales y sindicales han sufrido espectaculares replanteamiento s que nunca antes...habían sido imaginados...una de las variables más importantes,...es la anulación de facto de las conquistas laborales de los últimos cincuenta años, a partir de cambios legales, o de hecho, en los procedimientos de negociación..."( Cadena, 1995: 109).

El ideal del neo liberalismo es el de la existencia de un Estado que sea mínimo y al mismo tiempo que sea fuerte, donde se concilien las posiciones neo conservadoras y neo- liberales, en el caso de México, este fenómeno se está observando, ya que la tendencia va encaminada a un Estado mínimo con un gobierno fuerte.

\section{Mercado, Estado-Gobierno y la política social}

Uno de los instrumentos más importantes, para mantener la unidad y/o estabilidad económica, política y social, fue la política social y/o de bienestar social, misma que jugó un papel compensatorio y negociador muy importante hasta principios de los años setenta -dentro del Estado de bienestar-: “...durante los años de crecimiento sostenido se dio una vasta confluencia que permitió (en un acuerdo social implícito) la posibilidad de generar soluciones a las demandas de bienestar sin alterar sustancialmente la estructura política. Fue posible integrar la acción estatal con un triple propósito: promover la justicia social, crear incentivos y ganancias para los empresarios y mantener, con base en una sólida dominación corporativa, una larga estabilidad política...( económica y social)... Para la década de los setenta, aunque el petróleo y el crédito externo apoyaron financieramente la presencia de políticas sociales amplias, sobre las mismas bases, la crisis desplegada del modelo de crecimiento en los ochenta evidenció la creciente precariedad de este patrón de política social. Todo ello empezó a

tribuir el ingreso... (entre los factores productivos)...de acuerdo a sus 'productividades marginales' o aportaciones a la sociedad. A nivel internacional, la política del libre comercio,... lleva a aumentar las ganancias del intercambio para todos los países y finalmente a elevar el bienestar económico mundial" (Villarreal, 1983: 56). 
expresarse en una política social burocráticamente abultada y poco eficiente en sus beneficios a la población." (González, 1991: 25) Lo anterior queda de manifiesto en el comportamiento de algunos indicadores macroeconómicos, a saber:”...el PIB per cápita de 1988 fue equivalente al de 1977, los salarios mínimos reales de ese mismo año, tenían los niveles de 1963, el subempleo era semejante al obtenido dieciocho años atrás y el gasto público programable de 1988 fue igual al de 1974." (González, 1991: 19).

Siguiendo a Aguilar Villanueva, podemos decir que los años de crisis impusieron modificaciones en relaciones políticas y administrativas. La restricción de recursos obligó a redefinir los contornos de los ámbitos públicos y privados. Lo que ocasionó cambios en las responsabilidades del gobierno, de los individuos y de los grupos sociales. Lo que implicó que el Estado -ahora Estado neo liberal- desarrollara nuevas formas de hacer políticas, tales como: "Desincorporar, privatizar, desreglar, liberalizar, solidarizarse con los que menos tienen, corresponsabilizar a los demandantes o simplemente buscar calidad e imparcialidad en la prestación de los servicios públicos son ya nuevas formas de calificar y descalificar asuntos, interlocutores, agentes, procedimientos y argumentos. Se rompen pautas tradicionales de mediación, concertación, gesto ría, obtención de apoyos y consenso. No sólo empieza a cambiar la agenda de gobierno, desviando las demandas a organizaciones no gubernamentales, sino que también empiezan a cambiar los interlocutores y sus métodos de negociación” (González, 1991:33).

En estas circunstancias el viejo intercambio entre bienestar social a cambio de representación corporativa y obediencia no funcionan como en el pasado. Hemos llegado a los límites del paternalismo estatal, el tutelaje de éste sobre la población, está disminuyendo. Dicho proceso de disminución, es de por sí bastante difícil, y lo es mucho más si le agregamos el elemento cultural, pieza fundamental para dicho avance.

Hoy el neo liberalismo no ha hecho reaccionar a la economía mexicana. Los procesos llevados a cabo principalmente a partir del sexenio de Miguel de la Madrid, y que continúan a la fecha, como son: la liberalización de la economía, la apertura al comercio internacional, la desregulación económica, disminución del estado en las actividades económicas, reducción de la inversión pública, implementación de políticas de topes salariales, etc., son una muestra representativa que caracteriza al Estado neo liberal en nuestro país.

Así pues, a un poco más de 12 años de la imposición del modelo y la política neoliberal, sus efectos quedan de manifiesto sobre la sociedad. José Luis Calva diría que "Los programas neo liberales de ajuste económico y estabilidad fanáticamente aplicados en México durante 12 años, produjeron una deuda social muy superior a la externa." (Calva, 1995: 33). 
En síntesis, podemos decir que el incremento de salarios por debajo de los niveles de inflación y la incapacidad del modelo económico para la creación oferta de empleos, para satisfacer la demanda de la fuerza laboral -tanto la desempleada, como la que se incorpora continuamente- propicia- ron una mayor concentración del ingreso; lo que ocasionó, por una parte, crecientes niveles de marginación y pobreza, y por otro, mayor concentración de riqueza en algunos estratos sociales:

Con cifras del INEGI, Juan R. Jiménez, investigador del ITESM, demostró en 1994 que "el 60 por ciento del ingreso que anualmente se genera en el país lo reciben 8 millones 650 mil mexicanos, que representan el diez por ciento de la población,...y...ello por ciento de las percepciones anuales se reparte entre 59 millones de personas, es decir, 60 por ciento de la población del país" (Jiménez, 1994)

Así también "En México, a finales de 1993 y nada hace suponer que las cosas sean en este momento distintas y, más bien, podrían haberse agudizado: existían 13.6 millones de personas viviendo en condiciones de extrema pobreza.

Esos 13.6 millones de mexicanos representan el 16.2 por ciento de los 84 millones de habitantes del país; además, había otros 23.6 millones de personas (28.1 por ciento de la población total), que medianamente satisfacen sus necesidades de alimentación y algunas otras elementales, esto es, simple y llanamente viven en la pobreza...más del 40 por ciento de los habitantes...se debaten entre la pobreza y la pobreza extrema.

En el otro extremo, el año pasado la revista Forbes publicó la relación de los...más ricos del mundo, aquellos cuya fortuna personal excede los mil millones de dólares: eran 358...Entre...(estos)...se encontraban 24 mexicanos, cuya fortuna conjunta ascendía a 44 mil 100 millones de dólares, cantidad que al momento de publicarse la lista (Julio de 1994) duplicaba las reservas de divisas del país y era equiparable al 14 por ciento del PIB estimado en 1994." (CIEAP-UAEM, 1995,5-6). Por otra parte tenemos que "En materia de vivienda, la calidad de servicios de salud y en general en el resto de las necesidades básicas, con déficit históricos...importantes, la década do los años ochenta vino a contribuir...(significativamente)...a dichos déficit..EI banco mundial en su informe anual sobre la miseria... (Dice que)... 'las erogaciones sociales en México disminuyeron: la educación pasó de 16.4 a 7.4\%; la salud de 4.5 a $1.1 \%$ del total del gasto gubernamental'; en contraste el gasto militar y policiaco se mantuvo, y el pago de la deuda externa ascendió a 69.3\% del gasto público en 1988. Sin duda alguna, la política del gasto público es una de las facetas más lamentables de los años ochenta." (Alba y Cabrera 1994: 238). 
Ante la caída del gasto social, el empleo estable y remunerado son quizá las causales más relevantes de bienestar; ya que a través de éste se da realmente una distribución del ingreso. Sin embargo la incapacidad de la estructura económica para absorber la fuerza de trabajo que se va incorporando al mercado -PEA-, y el desempleo acumulado, da por resultado altos niveles de desempleo y subempleo. "Se sabe que en abril de este año de los 36 millones $750 \mathrm{mil}$ personas que constituían la PEA del país, 21 millones 500 personas ( 58.5 por ciento del total) se encontraban ocupadas en las actividades informales, en tanto que apenas 15 millones 250 trabajadores (41.5 por ciento de la PEA) se empleaban en el sector formal" (Gutiérrez, 1995: 3A).

Así tenemos que el modelo neoliberal es un modelo que, indudablemente, desaprovecha el potencial productivo que conforma la población ofertante de mano de obra y que no demanda la economía formal; ante tal hecho, dicha población tiene como último recurso, incorporarse a la llamada economía informal. De aquí que el futuro ocupacional de la población sea bastante incierto. Según cifras proyectadas presentadas por Campem Oxford Economic Forecasting se estima que para el periodo 1994 a 1995, la PEA crecerá 3.5 por ciento y el empleo total 3.5; así también se menciona que el empleo formal disminuirá en un 3.3 por ciento, mientras que el empleo informal crecerá en 8.1 por ciento.(La jornada, 1994)

De lo expuesto anteriormente, se concluye que: "El actual proyecto económico del país difícilmente cristalizará con una población depauperada. Mayor competitividad y productividad suponen mejores condiciones de vida; mayor educación implica fuerza de trabajo más capacitada, así como una adecuada alimentación es indispensable en el desarrollo de aptitudes físicas para el trabajo; distribuir las posibilidades de consumo significaría ampliación del mercado interno, etc. Parecería ser que, dados los grandes niveles de concentración de la riqueza que prevalecen en México, el argumento de que es necesario crecer para después distribuir no es en absoluto cierto. Debería insistirse en una voluntad política capaz de propiciar los mecanismos de distribución que en México no existen, y cuya ausencia puede ser la causa principal de la abismal desigualdad... (y)... de la paralización del aparato económico." (Alba y Cabrera, 1994: 246). 
Convergencia Revista de Ciencias Sociales, núm. 12/13, 1996, Universidad Autónoma del Estado de México

\section{Necesidad de un modelo alternativo del desarrollo}

\section{$Y$ después del neoliberalismo ¿qué?}

"Hoy frente a la crisis, el neoliberalismo juega la carta de la recesión y la austeridad. Su objetivo ya no es tanto el crecimiento del producto bruto sino el de las ganancias en una producción que se estanca. En realidad se trata de una operación conservadora por excelencia. Ya no se apunta a la creación de nuevas riquezas sino a la redistribución de las riquezas ya existentes. La preocupación exclusivamente monetarias corresponde a las exigencias de esta nueva lógica: sacrificar la economía para salvar la moneda”. (Villarreal, 1983: 41)

Pero, ¿realmente la crisis hoy vivida se debe a las deficiencias del mercado y del Estado-gobierno? Podemos decir que “...el fracaso del mercado no es necesariamente un argumento para la intervención del gobierno. Es necesario decir que en la actualidad hay también fracasos del gobierno. Así, de igual manera, un fracaso del gobierno no es necesariamente un argumento a favor del mercado. Sólo la experiencia en la práctica pueden demostrar cuándo y dónde es menos nociva la intervención. El reto consiste en diseñar instituciones que combinen recursos de la iniciativa privada con objetivos sociales y con la responsabilidad pública" (Streeten, 1993: 1295).

Además debemos tener presente que tanto el mercado como el gobierno, no precisamente fracasaron, sino quizás más bien, sus éxitos fueron los que condujeron a la actual crisis, es decir, el funcionamiento del mercado está sustentado en la optimización individual, generadora de una distribución muy desigual de la riqueza. Entre más éxito tiene el mercado, por su lógica concentradora y centralizadora, en general, más se incrementa la desigualdad -desigualdad que en el mejor de los casos no es absoluta, sino relativa-, y mucha gente está en la pobreza-. De igual manera, quizá no es el fracaso de gobierno, sino más bien su éxito en la persecución y alcance de los objetivos personales de la familia política -principalmente- lo que ocasionó los resultados que hoy viven los ciudadanos. De aquí que sea necesario un cambio estructural, una redistribución de la riqueza, y mayores oportunidades de participar en el ámbito político, en otras palabras, la existencia real de tener oportunidades en lo económico, en lo político y en lo social.

Ante tal situación, ¿cuál es la alternativa para superar la crisis dentro de un contexto capitalista como México? Si bien es cierto que el siguiente comentario, cae fuera del contexto de la crisis mexicana, no es menos cierto que tiene su importancia ante la falta de alternativas teóricas que hoy vivimos, e invita a la reflexión cuando nos preguntamos ¿y ahora por dónde o hacia 
dónde o qué debemos hacer?, dicho comentario es el siguiente: la caída del llamado "socialismo real" provocó el, llamémosle, desprestigio temporal de una propuesta socialista sustentada en el marxismo, y aunque poco a poco los duros hechos de la vida económico-social están llevando otra vez a los países del antiguo Bloque del Este a darle su voto a los excomunistas y/o socialistas (el último hecho de este tipo fue la derrota de L. Walesa, en las elecciones en Polonia), en busca de un bienestar social que se les negó, obviamente que falta mucho para que exista una opción económica política y social, de corte digamos socialista (quizás con otro nombre), que sea aceptada por los grandes sectores de la sociedad, sin embargo la tendencia señalada por la historia es volver los ojos a las teorías socialista y/o humanistas.

\section{Mientras tanto ¿que hacer? ¿Cuál es la opción?}

Reconocemos, como lo expuso John Bryson, de la Universidad de Minnesota, hace algunos años "En el pasado, dejamos trabajar los mercados hasta que fallaron; entonces respondimos con burocracias públicas. Estamos luchando para encontrar un nuevo camino, en algún lugar entre los mercados y la burocracia pública. Hasta ahora no hay ninguna teoría que lo guíe. La gente no tiene una idea clara del por qué las prácticas del pasado no funcionan, ni tampoco lo que debe ser un nuevo modelo...no hay un marco de trabajo teórico que la gente pueda usar para integrar sus experiencias." (Ángeles -coord.-, 1994: 21). Esto es, estamos viviendo una fuerte crisis de ideas.

\section{$Y_{\text {¿entonces? }}$}

René Villarreal dice que "La solución no está en regresar al Estado policía o vigilante del libre comercio ni en un Estado más grande, sino en un nuevo Estado cada vez más democrático en lo político y más racional en lo económico. El Estado en sus funciones de rector, planificador, inversionista,.. .regulador, promotor, banquero,... .debe ser más eficaz y eficiente pero debe actuar paralelamente con mayor justicia, representatividad y democracia..." (Villarreal, 1983: 17).

Así también, Fausto Alzati menciona que "El Estado debe -sin duda alguna- jugar un papel protagónico en este cambio histórico. En...México... continúa siendo el Estado quien puede orientar la configuración de una nueva economía capaz de competir con ventaja en el contexto internacional, a partir de un importante tejido productivo interno. En esta perspectiva, tan falaz puede resultar una equidad social que no se fundamente en la producti- 
vidad como ofrecer incrementos de productividad que no se sustenten en un incremento y mejor nivel de vida de la población. Combinar en forma virtuosa la competitividad externa con el bienestar de la población como parte de un proceso dinámico pasa por una importante articulación y especialización de las estructuras productivas internas y el fortalecimiento del mercado doméstico." (González, 1991: 63).

Si bien es cierto que el Estado seguirá jugando un papel importante en el futuro, no todo lo puede ni lo debe hacer éste. Cada vez un mayor número de actores deberán participar y tomar acuerdos en materia de política de bienestar social; es decir ésta deberá darse en un contexto que conlleve a fundamentarla a través de la construcción de una política pública, es decir, socialmente construida. Donde el Estado deberá jugar un rol de regulador -de la producción privada y de las ganancias, de la calidad y los precios, etc.- y coordinador, pero por ningún motivo deberá convertir su accionar en una actividad monopólica.

Bajo la perspectiva de la relación capital-trabajo, ésta deberá darse bajo nuevas formas de relación compartida entre los sectores público, privado y laboral, en palabras de Hernández Juárez "No basta la voluntad de los sindicatos para no confrontar, hace falta la voluntad del gobierno y de las empresas, así como una nueva cultura laboral en los trabajadores, en los administradores, privados o públicos, y en los dueños del capital. Cultura nueva que tendrá que entrelazarse en un nuevo pacto social y político, sustentado en relaciones y estructuras democráticas y con múltiples expresiones: acuerdos sobre capacitación, empleo, calidad y productividad, mejoramiento de las condiciones de vida y de trabajo, introducción de nuevas tecnologías, todo ello,...supone también una actitud no subordinada sino creativa y participativa que, en mi opinión, puede dar a la clase...(trabajadora, una mayor participación en lo) político y social, respecto de etapas y contextos anteriores en los que pretendía destruir más que transformar el Estado y los sistemas económicos y políticos." (Hernández, 1990)

Lo que hemos venido citando anteriormente, dista mucho de ser una posición de simplismo neoliberal o estatista, ya que no se señala que la provisión estatal de servicios sociales siempre es mala, y que la privada está llena de virtudes; ni tampoco se está cayendo en el extremo opuesto, en el sentido de que las actividades del Estado deben estar siempre presentes. "Si una política pública ha de ser pragmática tiene que aceptar los casos en que podrían funcionar de mejor manera las alternativas no estatales y de igual forma, defender aquellas modalidades de prestación estatal de servicios que puedan corregir las fallas endémicas de los mercados. Sobre todo debe reconocerse,... que los 
mercados no son creaciones naturales sino humanas: siempre han sido legal y políticamente estructurados. Por tanto, la alternativa no se da entre lo estatal y lo privado. Más bien. Hay que determinar cuáles de las múltiples estructuras mixtas (públicas)...funcionan mejor. Y ese mejor no se puede limitar al solo objetivo de la eficacia, pues cualquier evaluación razonable de necesidades alternativas, debe tener en cuenta consideraciones de justicia, seguridad y de ciudadanía” (González, 1991: 104).

\section{A manera de conclusión}

Así pues, tenemos que la situación de crisis que vive el país, por lo menos las evidencias dicen que, a través de las fuerzas del mercado, difícilmente se superarán los problemas en lo económico, en lo político y en lo social. Esto queda mostrado en los, aproximadamente 13 años de neoliberalismo vivido en nuestro México, con un balance muy desfavorable en los niveles desarrollo social, ya que los niveles de bienestar han caído en los últimos seis años, lo ganado en los anteriores cuarenta años, esto se observa en los niveles de pobreza alcanzados actualmente.

La reconversión en las formas de negociación política- económica-laboral, ocasionaron nuevas formas de redistribución del ingreso. Donde jugó un papel muy importante la intervención y/o desintervención del Estado.

Las políticas estatales intervencionistas, hasta inicios de la década pasada, a pasar de no haber sido ese su propósito, fueron generando y agudizando la crisis, al ir aumentando de manera extraordinaria su gasto público, lo que lo llevó a una situación insostenible -estado proteccionista, que generó ineficiencia e improductividad en los sectores público y privado-, que trajo consigo, endeudamiento externo, inflación, recesión, desempleo, entre otros efectos; lo que provocó el debilitamiento de la estructura productiva y de la estructura política.

Lo que demuestra que es falsa la disyuntiva que en muchas de las ocasiones se plantea, o todo al mercado o todo al Estado. Estos, mercado y Estado, por sí solos han demostrado su incapacidad para resolver los problemas de mantener el crecimiento, ya no digamos de desarrollo sostenido, ni mucho menos de desarrollo sustentable. De aquí que hoy más que nunca, debamos reflexionar profundamente, sobre el modelo que deberemos seguir, modelo encaminado a lograr una adecuada relación entre el mercado y la intervención del Estado -desregulando o regulando-, donde intervengan, los actores representantes de los sectores económico -empresarial y laboral-, político y social, en la discusión y concertación de la política económica y social, que redunde en un mejoramiento de las condiciones de vida de la población, es 
decir, en la elevación de los niveles de bienestar; de tal manera que tiendan a ir desapareciendo los altos niveles de pobreza que existen en el país.

Así tenemos que el futuro modelo -al menos en las condiciones actualesdeberá estar sustentado por la participación del mercado y el Estado, pero de manera acotada y/o regulada, respetando espacios para sí, espacios donde su intervención sea más conveniente, para la reactivación eco- nómica y un desarrollo social que garantice una distribución menos desigual entre la población.

Esto nos lleva a una dinámica de análisis que nos comprometa más con nuestra capacidad creativa, para ir explorando y construyendo nuevas alternativas para enfrentar la crisis que hoy en día estamos padeciendo.

Por último debo decir que lo anterior deberá darse en un ambiente que garantice una participación más democrática, lo que implica una descentralización política y una desconcentración económica, reales.

\section{Bibliografía}

Alba Francisco y Gustavo Cabrera, 1994: La Población en el Desarrollo Contemporáneo de México, México: El Colegio de México.

Ángeles Luis (coordinador), 1994: Reformas de Gobierno y Politicas Públicas, Toluca: Colección "Ideas para la Cultura y la Democracia.

Bobbio Norberto, 1986: El Futuro de la Democracia, México: FCE.

Cadena Edel, 1995: Sindicalismo y Neoliberalismo en México (1982-1992) Tesis de Maestría. México: UAEM.

Calva José Luis, 1995: "La Deuda Social y la Oferta de Bienestar para la Familia”, en El Financiero, marzo 10.

CIDAC, 1990: Reforma del Sistema Politico Mexicano: Condición para la Modernización, México: CIDAC.

CIEAP 1995: Papeles de Población, No. 8, julio-septiembre. Toluca, México: UAEM.

González Tiburcio Enrique, 1991: Reforma del Estado y Politica Social. México: INAP.

Gutiérrez Elvia, 1995: "Se Intensifica la Expulsión de Fuerza de Trabajo al Sector Informal”, El Financiero, abril 19.

Hernández Juárez Francisco, 1990: “Se Requiere un Cambio Radical”, en Examen, año 2. No. 14, julio. México: CEN del PRI

Jiménez Juan Ramón, 1994: La Jornada, julio 14.

Omelas, Jaime, 1995: en Papeles de Población No. 8 julio-septiembre. México: UAEM. 
Rodríguez Araujo, Octavio, 1991: "El Sistema Político Mexicano en la Perspectiva Democrática” en Transiciones Politicas, Colección Política y Administración, Tomo 1. México: Colegio Nacional de Ciencias Políticas CNCP.

Streeten, Paul, 1993: "Markets and States: Against Minimalism" en Word Development”, Vol. 21, No. 8. Greant Britain.

Villarreal René, 1983: La Contrarrevolución Monetarista, México: Océano. 